\title{
BETWEEN THE FAMILIAR AND STRANGE: UNDERSTANDING GOOD TEACHING IN TRANSNATIONAL EDUCATION SETTINGS
}

\author{
Marian Riedel ${ }^{1}$ \\ Vancouver Island University, Canada \\ Rachel Moll \\ Vancouver Island University, Canada
}

\begin{abstract}
Little has been written about how or whether pre-service teachers construct understandings of good teaching during an international field placement; thus, a need arises to examine these contexts as sites to question, "How do we know what we know?" (Britzman, 2003, p. 58). Based on a qualitative study of six pre-service teachers participating in an international field placement within transnational education school settings - meaning the academic program and provider, as opposed to the student body, have moved from a home country [i.e., Canada] to a host country [in Asia] (Knight, 2016) - this article identified that comparative settings problematized understandings of good teaching. Central to these findings is situating understanding between what is familiar and that which interrupts understanding (what is strange), and dialogue as the medium by which understanding is made public. To move beyond a theory-into-practice paradigm in initial teacher education, results highlight a need to foster comparative experiences to engender change and challenge status quo narratives of what it means to teach and learn in teacher education.
\end{abstract}

Keywords: international field placement, transnational education, hermeneutics, initial teacher education

\section{Purpose \\ As a central pillar of democracy, public education, and the educating of teachers within it, has the potential to foster change. However, when good teaching is generally understood as an application process in which knowledge acquired during on-campus teacher education \\ ${ }^{1}$ Correspondence: Marian Riedel, Faculty of Education, Vancouver Island University, 900 Fifth Street, Nanaimo, BC V9R 5S5, Canada Email: marian.riedel@viu.ca}


course work is applied in K-12 classrooms, good teaching is positioned as a techno-rational activity. Such a paradigm seems to permeate most teacher education programs (Ben-Peretz, 2011; Christou \& Bullock, 2013; Martin \& Russell, 2005) and situates initial teacher education as 'training' focused on practical skills, pedagogical classroom knowledge and 'what works' (Cochran-Smith, 2004; Loughran \& Russell, 2007). A theory-into-practice conceptualization of initial teacher education is perpetuated and has become "so implicit in most programs that we tend to be unaware of it and thus fail to critique it" (Russell, Martin, O'Connor, Bullock, \& Dillion, 2013, p. 11). Consequently, good teaching is depicted as an epistemological concern to be addressed by acquiring propositional and procedural knowledge, and knowledge and insights gained from the direct experience of teaching are marginalized. This "monological process constitutes training, not education" (Britzman, 2003, p. 46) and contests understandings of good teaching conceptualized as phronetic practical knowledge, "the kind of practical wisdom that is situational...(developed through experience)" (Russell et al., 2013, p. 32-33).

Without comparative experiences wherein "things change and become their opposite [once] one consistently thinks them through" (Gadamer, 2004, p. 460), pre-service teachers are apprenticed into a traditional system that seeks to flatten and homogenize practice rather than challenge it. Opportunities to change the status quo narratives of what it means to teach and learn, arise when comparative experiences are provided in initial teacher education. However, when techno-rational elements - the how and the what of teaching - are emphasized, the dialogical, agentic, anti-oppressive potential of teacher educators (and future teachers) as change agents within their schools and communities is lost. To interrupt the duplication of a techno-rational understanding of good teaching and situate initial teacher education as an agent of change, it is necessary to problematize the depiction of good teaching as a technical application situated within a theory-into-practice paradigm.

The purpose of this study was to explore how a direct experience of an international field placement in a transnational education (TNE) school setting - meaning the academic program and provider, as opposed to the student body, have moved from a home country [i.e., Canada] to a host country [in Asia] (Knight, 2016) - might provide an innovative space for pre-service teachers to interrupt understandings of good teaching. This article is based on a qualitative study of a small group of pre-service teachers from a small semi-rural teaching university in Canada who participated in such a placement. In line with exploring how comparative international experiences can be the impetus for change, understanding in this article is situated within a hermeneutic framework where understanding forms our primordial way of being in the world (Bernstein, 1983, p. 34) and truth is not reducible to a set of abstract criteria, rather it is an "experience in which we find ourselves engaged and changed" (Barthold, 2012, "Hans-Georg Gadamer (1900-2002)," para. 4).

International field placements have increasingly been offered within initial teacher education (Buczynski, Lattimer, Inoue, \& Alexandrowicz, 2010; Lee, 2011) and are generally situated within a study abroad context (Kabilan, 2013), with traditional internationalization post-secondary activities designed to "enhance the competitiveness, prestige, and strategic alliances” (Altbach \& Knight, 2007, p. 293). Little has been written about how pre-service teachers construct understandings and judgments about teaching in such environments. Less has been written from a Canadian perspective, and virtually nothing has been written about the comparative experience of teaching in a Canadian TNE setting where students are studying Canadian K-12 public curriculum "without moving to the country that awards the qualification” (Knight \& McNamara, 2015, p. 3). 
Canada currently authorizes 125 transnational elementary, secondary or combined elementary and secondary schools (CICIC, 2019). Over $77 \%$ are in Asia, with over $70 \%$ of those based in China, and the western province of British Columbia (BC) authorizing the greatest number $(36 \%)$ of schools. The results of the study suggest that the innovative approach of providing an experience of teaching outside of a familiar home-based placement (i.e., in a TNE context) using a familiar curriculum can provide a space where understandings of good teaching can shift and thus generate change.

Techno rationality in teacher education. Generally, initial teacher education curriculum within the academy in Canada is composed of a combination of coursework representing primarily propositional knowledge about who is taught (the learners), what is taught (subject matter and curriculum), where it is taught (context), why it is taught (foundations of teaching), and procedural knowledge of how it is taught (principles, practices and methods of teaching) (Gambhir, Broad, Evans \& Gaskell, 2008, p. 15). As Russell et al. (2013) outline, a theory-into-practice approach is "the fundamental framework. . implicit in the pre-service teacher education programs throughout North America” (p. 10). It implies propositional and procedural knowledge is acquired within the academy and subsequently applied unproblematically in practice settings.

With the academy regarded as "the place where [good teaching] knowledge was discovered and the [field placement] school [is] the place where it [is] applied" (Eisner, 2002, p. 378), good teaching involves the pursuit of the best/right practices and techniques as designated and learned in the academy to solve problems in the daily practice of classroom teaching (the field) (Bullock, 2011). As such, the approach marginalizes "learning from firsthand [direct] experiences . . . [or from] listening to oneself and to one's students" (Russell et al., 2013, p. 11). Consequently, the process of "becoming a teacher [is] no more than an adaptation to the expectations and directives of others and the acquisition of predetermined skills - both of which are largely accomplished through imitation, recitation, and assimilation" (Britzman, 2003, p. 46).

As a key element of initial teacher education, the field placement is where pre-service teachers participate in supervised and evaluated teaching situations in classroom settings (Crocker \& Dibbon, 2008; Gambhir et al., 2008). It is of "fundamental value in the process of becoming a teacher...; [ [however, it] is so taken for granted that the underlying structures and assumptions that authorize it are rarely interrogated" (Britzman, 2003, p. 49). As an opportunity to put theory-into-practice, this direct experience is also "shaped in powerful ways ... [where] learning can be constrained by advice from an experienced teacher and a university supervisor" (Russell et al., 2013, p. 12), and thus, pre-service teachers often ignore "that which does not fit with what [they] expect to find, assimilating the strange to the known” (Higgins, 2010, p. 322) during field placement. As a result, the field placement often does not become an opportunity to learn from, or gain valued experience; instead, experience is quickly marginalized and masked by propositional and procedural knowledge.

In effect, rather than an opportunity to explore propositional and procedural knowledge in relation to the real world of practice, the context of the field placement (including supervisory practices) often reinforces the idea of good teaching as a technorational, quantifiable, skills-based activity. The learning gained from the direct experience of teaching is not used to explore the complexities, judgements and individual relationships that inform good teaching. If the hope is for pre-service teachers to become change agents by problematizing their own understandings and direct experiences of good teaching, it will require "more from teacher preparation than simply 'training'; it requires educative experiences purposefully embedded in meaningful pedagogical situations [italics in the original]” (Loughran \& 
Russell, 2007, p. 222) where conflicting notions of education in particular contexts can be analyzed and tested both privately and publicly by pre-service teachers. As such, might an international field placement in a TNE school setting allow pre-service teachers to approach the understanding of good teaching as necessarily "problematic in its social construction ... [and] question, how do we know what we know?” (Britzman, 2003, p. 58).

International field placements. More recently, international field placements have been offered in initial teacher education programs with some Canadian institutions "experimenting with international practica as a potential site for the professional and personal development of teacher candidates" (Culligan \& Kristmanson, 2014, p. 63). Existing research on these projects focuses on impacts, such as cultural and global awareness, that prepare preservice teachers to cope with today's diverse classrooms (Cushner \& Mahon, 2002; Malewski, Sharma, \& Phillion, 2012; Myers, 1997; Stachowski \& Sparks, 2007). With calls for teachers to be "equipped to prepare all students for their roles in this diverse world" (ACDE, 2005), literature positions such professional and personal development as a response (or solution) to these calls and research supports this call (Buczynski et al., 2010; Lee, 2011). However, good teaching is generally still situated as the application of propositional knowledge (namely one focusing on what culture exists within the host location) and procedural knowledge (namely how one is to teach students from diverse cultural backgrounds). Good teaching remains an "external reality that is then reinforced and practiced" (McGregor, Stanford \& Hopper, 2010, p. 298). Thus, despite the call for more research documenting pre-service teachers' experiences of international field placements (Brindley, Quinn, \& Morton, 2009; Trilokekar \& Kukar, 2011), much of the current research speaks to a theory-into-practice conception for international field placement where the new knowledge of enhanced cross-cultural knowledge, awareness, sensitivities and skills gained during the placement are perceived to lead to increased professional competence (Maynes, Allison, \& Julien-Schultz, 2012). There is seemingly little critical analysis by participants (i.e., pre-service teachers) of the underlying premises upon which good teaching is based. As Ben-Peretz (2011) notes, this international focus has simply resulted in globalization being added to the existing propositional knowledge to be acquired during initial teacher education programs. The international field placement is now framed as a "means to an end" to achieve a predetermined outcome (e.g., global awareness, multiculturalism, or diversity).

Little has been written about how or whether pre-service teachers construct understandings of good teaching during an international field placement. Thus, a need arises to examine international field placements as sites for pre-service teachers to question, "How do we know what we know?" (Britzman, 2003, p. 58). In response to this need, this study asked "How might the direct experience of international placement inform or challenge assumptions embedded in notions of good teaching?" and "How do such direct experiences provide enhanced opportunities for pre-service teachers to try out competing, or even conflicting, understandings of good teaching?" This study examined these questions in the context of TNE settings using curriculum from British Columba (BC), Canada where little to no research has been conducted.

With the international field placement regarded as another "discrete and arbitrary unit" (Britzman, 2003, p. 51) to be aligned with a theory-into-practice model of initial teacher education and field placements conceptualized as an opportunity to apply, test and replicate theory/understandings of good teaching, there are missed opportunities for pre-service teachers to problematize understandings and judgements about good teaching. Positivistic orientations to teacher knowledge and educational research (Biesta, 2007; Eisner, 2002; Russell et al., 2013) do not invite pre-service teachers to explore their ideas about good 
teaching. "Experience becomes not organic, interactive, and continuous but rather something scripted, timed, and located" (Roberts, 2005, p. 15). One way to address the challenge of facilitating educational change is to recognize the absence of consideration in the actions of good teaching, as well as the marginalizing of opportunities for pre-service teachers to question or problematize the multiple, conflicting notions of what constitutes good teaching within a different context, such as an international field placement. Given the possibilities inherent in an international field placement (Brumberger, 2007), what if we attended carefully and gave voice to the understandings gained via direct experiences of teaching for pre-service teachers during an international field placement? Might this be an opportunity for change; a widened horizon enriching teaching with "a whole new and deeper dimension" (Gadamer, 2004, p. 391) of good teaching?

\section{Theoretical Framing of Understanding and Experience}

In this study, philosophical hermeneutics - specifically that articulated by HansGeorg Gadamer (2004) - was used to define understanding; where understanding is viewed as "an interpretive practice that occurs in a shifting in-between, in the middle of relationships, contexts, and particularities" (Moules, McCaffrey, Morck, \& Jardine, 2011, p. 2) where one "can only understand the parts [of good teaching] in terms of the whole [of good teaching] and vice versa [italics added]" (Higgins, 2010, p. 321). Gadamer's (2004) hermeneutics provides useful resources to frame how individuals create understanding and make judgements by addressing the historical conditioning of understandings and actions, followed by exploring the prejudices and traditions that inform and normalize those understandings and resultant actions. By highlighting particular forms of dialogue, the hermeneutic circle frames the confrontation and interruption of general understandings, and the exploration of new or different horizons of understanding of good teaching and of different/new choices of action that could lead to change.

However, as Gadamer notes, "understanding is not, in fact, understanding better... It is enough to say that we understand in a different way, if we understand at all" (Gadamer, 2004, p. 296). Thus, the study's objective was not to achieve an ultimate understanding, or absolute truth, of good teaching or experiences during an international field placement. Instead, the hermeneutic framework changes the conversation from current conceptions, such as Britzman's (2003) notion of teacher knowledge resting in the authoritative discourse within the academy of initial teacher education, and generates alternate ways of thinking about how claims to truth and goodness are made in teaching and initial teacher education. It frames a perspective of understanding where "truth is not... what can be guaranteed by a method" (Grondin, 2003, p. 22) and contests the depiction of good teaching as an application activity situated in a theory-into-practice paradigm. Instead, by inviting a personally persuasive discourse which can extend, and change understanding, individual truths and goodness are revealed in dialogue where comparisons of what may be incompatible and incommensurable claims to truth can be made.

Furthermore, Gadamer's hermeneutics speaks to an ontology of understanding and implies "the continuing formation of the self in the light of experience, beyond the sheer acquisition of experiences" (Moules, McCaffrey, Field, \& Laing, 2015, p. 46). In teaching, experience is generally a vague term, understood as the accumulation of time spent teaching in practice settings. Conversely, Gadamer's two concepts of experience, Erlebnis and Erfahrung, provide a more robust framing. Erlebnis describes daily events "that conform to our expectation and confirm it" (Gadamer, 2004, p. 347), while the defining quality of Erfahrung is "not confirmation of expectations leading to trustworthy generalisations but 
precisely disconfirmation [emphasis added]" (Higgins, 2010, p. 323). Erfahrung involves an interruption to understanding which "means that hitherto we have not seen the thing correctly and now know it better" (Gadamer, 2004, p. 347). Erfahrung experiences are often uncomfortable but are simultaneously "articulated by the notion of a 'learning experience' that ... serves to negate [and change] our previous views" (Warnke, 1987, p. 26). This dual perspective of "experience", expressed as familiarity and strangeness, was used to frame the direct experiences of an international field placement for the pre-service teachers in this study.

Specifically, this study examined how six pre-service teachers questioned, understood, and acted on their ideas about what it means to be a good teacher. By exploring interpretations and judgements of good teaching, as understood by pre-service teachers engaging in a direct experience of teaching in an international field placement in TNE school settings in Asia using the BC curriculum, this study offers a response to Britzman's (2003) statement that "student teachers rarely have the space and official encouragement to consistently theorize about their lived experience" (p. 64). This study examined the idea that an experience of teaching familiar curriculum outside of a familiar home-based field placement (i.e., in a TNE setting) may provide such a space not found in traditional theory-into-practice models of initial teacher education. Foundational to engendering change in understandings in such spaces, this study design recognized the key role dialogue must be able to play.

\section{Methodology}

For Gadamer, "truth is reached not through abstract constructions, but through dialogue" (Grondin, 2003, p. 12). Therefore, central to this study was dialogue framed as genuine conversation to gain understandings about good teaching. Several Gadamerian resources, including historical conditioning, tradition, and prejudices were used to explore the development of a horizon of understanding from which the participants interpreted their direct experiences. Direct experiences of teaching and how such experiences were understood as either familiar or strange during the international field placement generated the primary data for this study. Here, the Gadamerian resource of hermeneutic circle was used to explore how individual participants made meaning of direct experiences when integrating particular direct experiences as either familiar or strange into larger general contexts of teaching. The circular movement of particular direct experiences (the parts) and general understandings of teaching (the whole) aided in exploring the relationship between international field placement experiences and understandings of good teaching. In short, the process of understanding from a hermeneutic standpoint is "always from the parts to the whole and from the whole to parts, thus fulfilling the hermeneutic circle” (Liu \& Sui, 2014, p. 763). In sum, the study design was informed by a qualitative hermeneutic approach.

Data sources. Six pre-service teachers (5 elementary, 1 secondary) volunteered to participate in this study. All had been accepted into an international field placement program and were in their penultimate term of a post-degree initial teacher education program. Each had completed 45 days in a home-based field placement prior to participating in the study. The international field placement consisted of a four-week placement at three Asian based Canadian TNE schools using the $\mathrm{BC}$ curriculum. Participants were required to teach a halftime, or $50 \%$ load, and to participate in the "daily life" of their host school, which included participating in extracurricular and wider community events occurring during the placement. The international field placement involved no formal evaluation from field placement supervisors and was positioned as an 'additional field placement' in relation to the required field placements components of their initial teacher education program. 
Specifically, two schools in urban China and one in urban Thailand were involved in this study; one elementary, one secondary and one K-12. Within Knight's (2016) transnational education framework, all research sites fell into the independent or stand-alone category of TNE activity, meaning the host country is generally "not involved in the design or delivery of the academic programs” (p. 38). Despite this, studies (Knight \& MacNamara, 2015; Lim, 2016) note TNE is attractive to host country students from urban middle-income families in terms of affordability, pathways and preparation for foreign/overseas degrees, and the broader international outlook relative to local non-TNE schools. In terms of this study, despite the geographical, cultural, political and economic variations between each research site, programing, curriculum, school accreditation and credentialing activities were all situated within the BC Global Education Program (BCME, 2014) offered by the BC Ministry of Education. Arguably, the host TNE school site could be interpreted as a familiar schooling context for study participants as the school was founded and informed by the same policies and procedures that governed the participants' school placements in their Canadian home province of $\mathrm{BC}$. The key difference within the school context pertained to the student body. Consistent with Knight's (2016) framing of TNE schools, student enrollment consisted primarily of "host country domestic students as well as [some] expatriate students living in the host country" (p. 35-36).

Thus by situating the work within a Canadian TNE school context, significant differences in relation to how good teaching and schooling is understood from the perspective of the local host cultures (Thai and Chinese) was provided, while at the same time providing sufficient familiarity for participants to engage substantively as teachers during a short-term placement, and to potentially surface taken-for-granted assumptions about good teaching that may go unchallenged in a regular home-based placement in Canada.

Data collection. In keeping with a hermeneutic genuine conversation, as it is in dialogue with others "that understanding takes place" (Freeman, 2011, p. 547), creating opportunities for dialogue was fundamental in guiding the data collection methods. It was in the conversation between the researchers and study participants, as well as between the participants themselves, that understandings of good teaching were brought into being. Consequently, data collection was conducted predominantly via individual and focus group interviews held before, during, and after the international field placement. The interview method used was situated within van Manen's (1990) conversational interview framework, focusing on personal stories, anecdotes, recollections, or metaphors of lived/direct experiences that allowed for the interpretation of a horizon of understanding of good teaching.

The purpose of the individual pre-placement interview was to access the various Gadamerian resources, such as historical conditions, traditions, and prejudices, to provide an "initial orientation to that [good teaching] which we [this study was] trying to understand" (Warnke, 2002, p. 315). As hermeneutic work "is based on the polarity of familiarity and strangeness" (Gadamer, 2004, p. 295), the initial interview inquired about familiarity and strangeness participants predicted/expected to directly experience during the international field placement. In doing so, the context in which to frame the in-between place where new understandings of good teaching could be articulated. A pre-placement focus group interview was held with the purpose to provide a public forum in which to engage in dialogue around understandings of good teaching, as well as predictions of direct experiences of familiarity and strangeness. The goal was to see what kinds of new or different understandings might be generated in a group context.

Data collected during the international field placement utilized a two-pronged approach through a set of pre-service teacher e-journal entries and digitally recorded remote 
individual interviews. For the e-journal entries, participants were asked to write one entry (approximately 300 words) at the end of each week for a total of four entries throughout the duration of the international field placement. Within these entries, participants were asked to reflect on aspects of the placement that struck them as familiar and strange. Bi-weekly remote individual interviews provided conversational space for participants to expand upon placement aspects noted as familiar and strange in e-journal entries. Post-placement data collection consisted of one individual interview and one focus group interview in order to determine if understandings expressed during pre-placement individual and focus group interviews had altered and what new, or different, understandings might have emerged.

Data analysis. To analyze the data, Lincoln and Guba's (1985) three-part constant comparison method of "unitizing, categorizing, and thematizing" (Wang \& Clarke, 2014, p. 110) was employed. In this study, this successive data reduction process allowed for the constant comparison of what the participants found to be familiar and/or strange in relation to teaching before, during, and after the international field placement. The first step involved an initial line-by-line analysis of interview transcripts and e-journal entries to identify instances of familiarity and strangeness for each participant. Instances of familiarity and strangeness were then constantly compared with each other until distinct units of meaning relating to the practice of good teaching emerged for each participant. These units of meaning were compared further until distinct and unique categories relating to understandings of the practice of good teaching emerged. In total, six categories emerged.

A further level of comparison and abstraction - sought to identify overarching themes related to the pre-service teachers' interruptions to and new understandings of good teaching across all participants as a result of their international field placement - was completed. In total three broad themes emerged.

\section{Findings}

Six categories relating to familiarity and strangeness in understanding the practice of good teaching emerged: (a) Canadian/Western context, (b) classroom characteristics, (c) school setting, (d) staff relations, (e) student characteristics, and (f) teaching activities. There was overlap and interconnection between the categories with many being interpreted as dynamic and fluid areas of understanding. In relation to these categories, Table 1 outlines example of instances relating to teaching and the exploration of good teaching noted as familiar and strange by participants.

In using Gadamer's notion of Erfahrung to frame direct experiences in terms of an interruption to understandings of good teaching, it was within conversation with participants about the interconnectivity and fluidity of such experiences that current understandings were problematized, and new understandings emerged. Themes were identified as problematizing three important dimensions of understanding good teaching relating to: (1) the hegemony of embedded Western values in schooling; (2) universal applications of 'good' pedagogy/ 'best practice'; and (3) the pre-service teacher position within the field placement. Two of these themes are elaborated here with individual participant experiences used for support.

Problematization of the hegemony of Western values in schooling. In Figure 1, references to familiarity and strangeness as experienced before, during and after the international placement are summarized for all participants and illustrates how participants' awareness shifted throughout the experience to include problematizing Western values in schooling. Prior to participating in the international field placement, none of the participants explicitly predicted that their direct experience would surface greater awareness of their own Western values. Rather, predictions focused on the expected familiarity of daily activities of 
teaching (i.e., teaching methodology, daily teaching routine, classroom management, etc.). For example, Anne stated: "I'll go over there and be like, whoa, we do that at home? That's something I'm not going notice here [Canada] because... I am always in this environment, but I might notice the differences after I come back" (Pre-Placement Focus Group).

Table 1

Participant Examples of Familiarity and Strangeness Relating to the Practice of Good Teaching

\begin{tabular}{|c|c|c|}
\hline \multirow[b]{2}{*}{ Emergent Category } & Examples of Familiar Instances & \multirow[t]{2}{*}{ Examples of Strange Instances } \\
\hline & & \\
\hline $\begin{array}{l}\text { Canadian/Western } \\
\text { Context }\end{array}$ & $\begin{array}{l}\text { - working with Canadian } \\
\text { curriculum and resources }\end{array}$ & $\begin{array}{l}\text { - making Canadian curriculum } \\
\text { relevant to students } \\
\text { - conflict between Canadian } \\
\text { and host school student values } \\
\text { and perspectives }\end{array}$ \\
\hline $\begin{array}{l}\text { Classroom } \\
\text { Characteristics }\end{array}$ & - physical set up of room & $\begin{array}{l}\text { - smaller number of students in } \\
\text { class } \\
\text { - limited access to technology } \\
\text { - notions of classroom safety }\end{array}$ \\
\hline School Setting & - physical school building & \\
\hline Staff Relations & $\begin{array}{l}\text { - working with sponsor/host } \\
\text { teachers }\end{array}$ & $\begin{array}{l}\text { - dual cultures of staff } \\
\text { - high staff turnover rates } \\
\text { - surrogate family relationship }\end{array}$ \\
\hline $\begin{array}{l}\text { Student } \\
\text { Characteristics }\end{array}$ & $\begin{array}{l}\text { - personalities of age groups } \\
\text { - students being themselves }\end{array}$ & $\begin{array}{l}\text { - second language learners } \\
\text { - high homework completion } \\
\text { - different inherent/ } \\
\text { background knowledge } \\
\text { - acknowledge school as a } \\
\text { privilege } \\
\text { - pressure to succeed and } \\
\text { achieve }\end{array}$ \\
\hline Teaching Activities & $\begin{array}{l}\text { - act of teaching } \\
\text { - managing students } \\
\text { - lesson planning }\end{array}$ & $\begin{array}{l}\text { - act of teaching } \\
\text { - incorporating English as a } \\
\text { Second Language teaching } \\
\text { methods } \\
\text { - classroom management } \\
\text { methods } \\
\text { - homework levels }\end{array}$ \\
\hline
\end{tabular}

Her comments highlight an awareness that the international placement could become a new point of reference for determining difference given the Asian based geographical and cultural contexts, but the focus maintained an emphasis on propositional and procedural knowledge, consistent with the techno-rational, theory-into-practice paradigm of initial teacher 
education. However, during- and post-placement conversations highlighted a surfacing and problematizing of the Western centric perspective. As Santoro (2009) explains, "developing pre-service teachers' knowledge of the 'ethnic self' . . is difficult and challenging work . . . [requiring] teacher educators to unsettle what are students' [and possibly teacher educators' as well] deeply rooted beliefs" (p. 42). The implication from Anne's observations is that such work is not commonly occurring within the study participants' respective initial teacher education programs or home-based field placements.

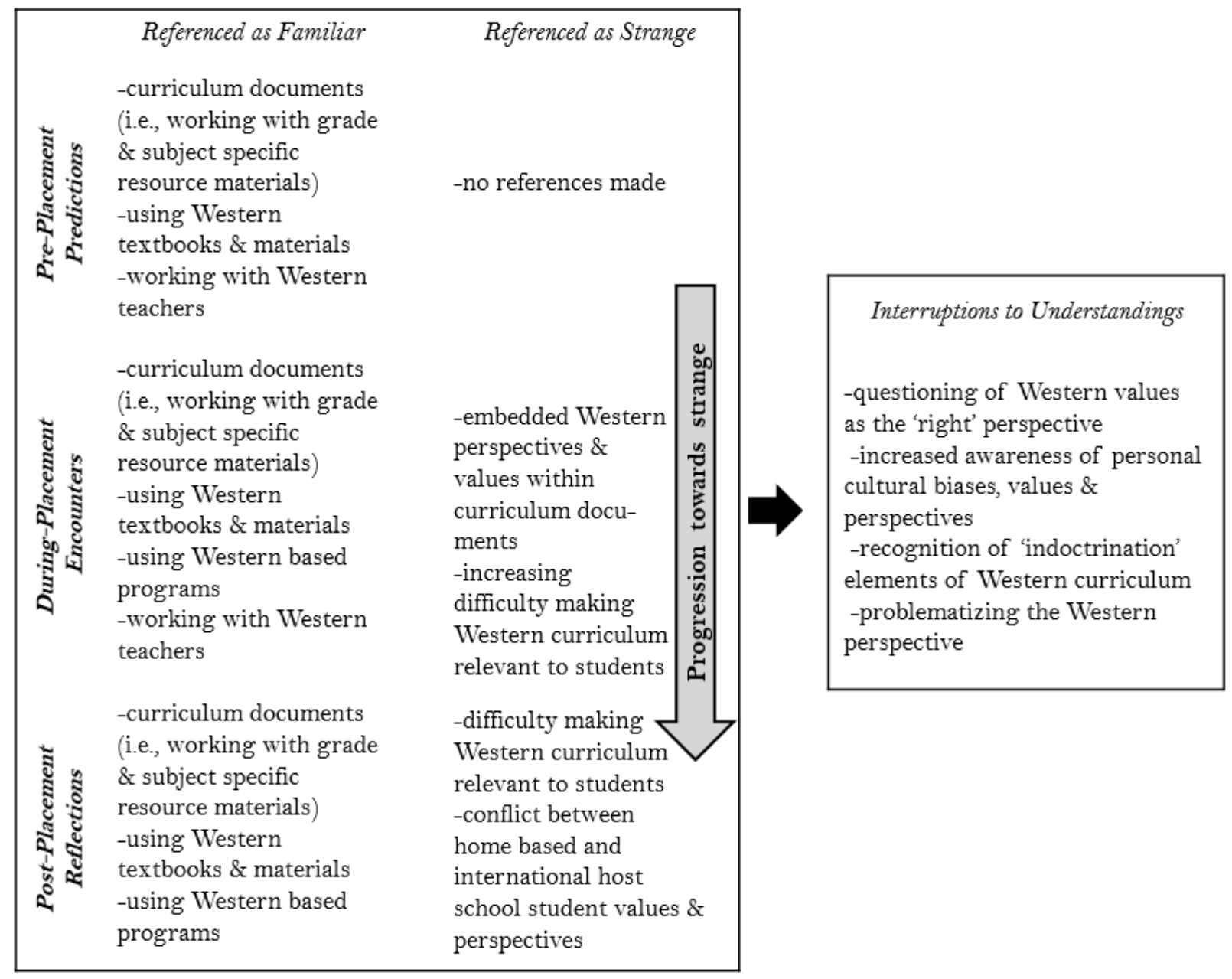

Figure 1. Summary of familiarity and strangeness problematizing the hegemony of Western values in schooling leading to interruptions of understandings.

As the international placement continued, and participants became more settled and familiar with their new teaching responsibilities and host school routines, the boundary between Western and non-Western values became increasingly contested and complex. This was particularly obvious in relation to interactions and encounters with the students of the host schools, many of whom were of non-Western heritage, or of mixed Western and Eastern heritages. For Cathy, it made it problematic which cultural perspectives to follow as the student body consisted primarily of "international students traveling to the TNE host country" (Knight, 2016, p. 36): "You have families from all over the world with different 
cultures operating in a Canadian school in Asia. So, it's like what rules are you following there, like whose rules do you follow?” (Cathy, E-Journal Entry Two).

The cultural contexts of China and Thailand also disrupted participants' attempts to teach and to "cover" Canadian curriculum content, surfacing a disconnect between the different cultural perspectives of the students and the Western based curriculum. For example, when using Canadian based resources incorporating BC wilderness images and contexts in an urban Thai setting, Matt notes: "one of the examples in the textbook is a fisherman on the Fraser River throwing his spear at a salmon . . The kids here are reading this [and] some of this stuff is completely different" (Matt, Post-Placement Interview). Matt began to problematize the appropriateness of using resources and content situated within Western centric perspectives and Canadian contexts. "All of [a] sudden, just through the tangibles [i.e., textbooks] in the classroom $I$ [emphasis added] can really relate, [but] it's completely different for the students" (Matt, Post-Placement Interview). This quote highlights the import/export feature of TNE programs with the curriculum and academic oversight stemming from the sending education program (the province of $\mathrm{BC}$ ) and the host school role of "providing the space, students, support services and program advertising" (Knight, 2016, p. 40). It also speaks to Matt's ability to relate to familiar elements of the TNE setting but, most importantly, highlights what became problematic for Matt: his students' inability to relate. The new understanding which emerged was the incompatibility between the nature and purpose of the school curriculum and the context of the students for whom the curriculum was intended. Thus, when Matt applied the Canadian curriculum in the different and unfamiliar context of the transnational school setting in Thailand, new understandings of the Western curriculum emerged. In consequence, the direct experience of teaching a Western centric curriculum to students from different, non-Western cultural and knowledge paradigms, surfaced and problematized certain taken for granted views embedded within Western worldviews. Similarly, Anne said, "I had to figure out ways to define words ... w words that I've never had to define before" (Anne, During-Placement Interview). She recognized that the students had "different inherent knowledge" (Anne, During-Placement Interview), as well as backgrounds, from which to process the Canadian curriculum.

By engaging in conversation with participants about interruptions to their understandings stemming from Erfahrung experiences, the "curiously productive meaning" (Gadamer, 2004, p. 347) of these experiences highlighted emergent new meanings. For example, Bella highlighted a potential shift in horizon of understanding in how a pre-service teacher may understand and act as a teacher in the future:

I try to see things from lots of different angles, but this international practicum experience definitely made me see some sides that I wouldn't have thought of before ... I think that will always stay with me and affect the way that I look at things in teaching. (Bella, Post-Placement Interview)

And Anne expressed during a post-placement conversation the power and bias embedded within Western schooling:

We view our values and ideals as an OK thing because we view the system that we live under as being $\mathrm{OK}$, a good and a right system, but like that's just a view we have, like who says it's right, you know? We're indoctrinating our students with these values [and] that's something I didn't really recognize 


\section{before. (Anne, Post-Placement Interview)}

As Alexander (2000) highlights, "comparison is actually essential to educational progress [and change]. Education positively requires, and positively benefits from, a comparative imagination and comparative understanding" (p. 27). As such, the direct experience of a comparative TNE teaching placement may surface how culture and pedagogy relate to and inform one another - not only in terms of how the host transnational schools enacted the Canadian curriculum, but also how the study participants understood their practice and actions of good teaching as someone from a Western culture and perspective teaching the same Canadian curriculum in a non-Western/international context. Furthermore, for all participants, the international placement was their first direct experience teaching their home-based curriculum to a student body that was not part of the dominant cultural majority for which the curriculum was originally intended. To echo Santoro and Major (2012), the curriculum that seemed "just normal" within the home-based field placement context, had become strange, or "othered" (p. 317). Thus, understandings that were once familiar, and taken for granted, began to shift.

Interpreted from a Gadamerian perspective, the direct experience of an international placement in a TNE setting provided an opportunity for participants to make more apparent the traditions that informed the construction of the Canadian curriculum and their own ideas about teaching, thereby surfacing the biases that underlie choices and determinations of goodness. Situating an international field placement in a transnational school setting was an opportunity for participants to consider what good teaching is without being totally overwhelmed by an entirely different setting. As Kerdeman (1998) points out, it is in being pulled "between familiarity and strangeness, we find ourselves in the middle of an on-going liminal experience, not quite at home in the world, yet not entirely estranged from it ... that makes understanding it possible" (p. 252). Thus, for the participants, an outcome of their international placement experience and the cross-cultural context in which it took place, was "not to replace the familiar with the new, nor to encourage identification with another culture, but to de-familiarise and de-centre, so that questions can be raised about one's own culturallydetermined assumptions and about the society in which one lives" (Byram, 2008, p. 31). If pre-service teachers are to be agents of change within their communities, they need opportunities to compare understandings of goodness in teaching. The results of this study demonstrated that an international placement in a transnational school setting provided a key comparative experience and highlighted that the potential to change understandings is not readily possible in a theory-into-practice paradigm of initial teacher education.

Problematization of universal applications of 'good' pedagogy/'best practice'. Participants' references to pedagogy provided evidence of increased problematization of concepts such as 'best practice' and universally applied pedagogies. Conversations during and after the international placement included over a hundred references of strangeness relating to teaching activities; conversely, pre-placement conversations predicted a great deal of familiarity with teaching activities. This was especially evident when the host TNE school contexts challenged the intended goals and outcomes of the participants' planned pedagogies. For example, key pedagogies and activities referenced as strange in the context of the international field placement included: lesson planning, classroom contexts of safety, English language acquisition, building student and parental rapport, and summative testing. This misalignment between the participants' intended goals of "good" pedagogy and direct experiences of "good" pedagogical implementation implied an interruption of general 
understandings of goodness and the assumed universal application of "good" pedagogy while raising an awareness of alternate "good" pedagogies (see Figure 2 ).

\begin{tabular}{|c|c|c|}
\hline $\begin{array}{l}\text { Pedagogies Shifted from } \\
\text { Familiar to Strange }\end{array}$ & & $\begin{array}{l}\text { Interruptions to } \\
\text { Understandings }\end{array}$ \\
\hline $\begin{array}{l}\text {-lesson planning } \\
\text {-safe environment for teaching PE } \\
\text {-English as Second Language teaching } \\
\text { strategies } \\
\text {-building rapport with students } \\
\text {-summative testing } \\
\text {-consequences of cheating } \\
\text {-parental involvement }\end{array}$ & $\Rightarrow$ & $\begin{array}{l}\text {-increased awareness of alternate } \\
\text { pedagogies } \\
\text {-questioning of "correctness" of } \\
\text { pedagogies } \\
\text {-shifting of familiar understandings to } \\
\text { awkward through to strange }\end{array}$ \\
\hline
\end{tabular}

Figure 2. Understandings of 'good' pedagogy.

Specifically, the act of lesson planning was generally understood by all participants as a familiar activity in pre-placement interviews. For some participants, the direct experience of planning for the transnational school context increased their awareness of, and appreciation for, the processes used in home-based placements, especially in relation to lesson planning thoroughness and expectations. However, conversations during- and postplacement highlighted changes in how participants viewed the "goodness" of the lessons planned. Participants made extensive comparisons with previous direct experiences of lesson planning in their home-based placements, where good planning was understood as incorporating a variety of differentiated teaching strategies, accommodations, designations, and an emphasis on classroom management. However, a key interruption in understandings of good lessons was articulated in relation to planning for a traditional learning context, where "students all had the same [lesson] expectations . ... and [worked] all at the same level" (Cathy, Post-Placement Interview), and challenged assumptions of goodness in differentiating teaching methods. In noting the misalignment between planning and intended outcomes, a math lesson involving the use of modeling clay was a key Erfahrung experience for Molly. Planned as an interactive teaching method and judged to be good by Molly because the students were "going to play and be kids" (Molly, Post-Placement Interview) while learning math, Molly described a completely different student response to the one that she had expected:

Half of the class didn't want to touch the modeling clay because it was dirty . .. and the other half wanted to make perfect symmetrical $3 \mathrm{D}$ shapes out of it. ... They didn't all hate the clay, but they all weren't super stoked on the modeling clay whereas I know if I had done that at home, it would have been like 'awesome' and the students would have learned a lot from it whereas the kids in Asia didn't really take a lot away from it. (Molly, Post-Placement Interview)

The direct experience problematized Molly's judgement of good teaching embedded within lesson planning where interactive learning, a key tenet of a Western approach to teaching and learning, is indicative of good lesson planning. By engaging in the direct 
experience of teaching in an unfamiliar context where interactive learning was not necessarily the norm, Molly's prejudices were challenged.

Furthermore, Molly's assumptions of "good" pedagogy in relation to building student rapport were also challenged when she applied various pedagogies used during her previous placements in Canada to achieve this outcome within the context of the TNE placement in China. In contending with a student body comprised of a mix of "host country domestic students as well as [non-Canadian] expatriate students" (Knight, 2016, p. 35) she found:

Students didn't want to build a rapport in the same way, with jokes and humour, that the kids in Canada do ... it never really felt like they cared about me in the same way as my kids at home did [who] wanted to give me hugs before I left . . I I could tell they genuinely really cared about me but here I don't think we ever really got to that level ... [it] always felt a little guarded, or at least I picked up on that. (Molly, Post-Placement Interview)

Molly's notion of the teacher-student relationship within the home-based context was based around ideals of friendship, while in China students maintained a greater distance in terms of personal engagement (perhaps out of respect) for the teacher. "You are the authoritative person in the classroom ... It was very much 'We respect her, she is the teacher and that's the way we treat her.' She's not a friend and I think that is where I found the difference" (Molly, Post-Placement Interview). Her understanding was based on a comparison between previous direct experiences of building rapport in home-based field placements and led to a problematizing of pedagogies used to build student rapport. It also problematized a general understanding and judgement that infusing humour into teaching is "good" pedagogy. For Molly, this interruption in understanding occurred in the Chinese context and challenged her assumption that "being yourself" is a good pedagogy for building rapport: "In being myself and bringing out my personality into the class I really like to joke around with my students ... that's how I build a rapport with the students at home but in China the students just didn't get the jokes in the same way ..." (Molly, Post-Placement Interview).

Finally, the use of summative tests, particularly tests designed to assess understanding of curriculum content via a unit test, was another example of a "good" pedagogy which was directly experienced as strange during the international placement. For Anne, based on her own direct experiences of summative testing as a high school student in the same environment in which she was currently a pre-service teacher, such assessment was initially understood to be "good" pedagogy to determine levels of student knowledge of the curriculum. However, upon directly experiencing summative testing in the TNE school based in China, notions of goodness within this pedagogy were problematized, and led to a shift in determining the goodness of such an assessment strategy in a senior level class:

For the most part my students were getting the content and then they wrote a standardized [multiple choice] unit test. My class average was 30 percent and some students got 15 percent. I was sitting there looking at them and thinking these students know way more than 25 percent of the information on this test ... So then I'm, like, okay, what is this testing because this clearly is not a good representation of what my students know. ... The results did not represent what they know in the slightest! So then I'm like what was the point of that then? . . . The experience totally completely changed my opinion of 
multiple-choice tests and testing students in that way. It made me mad. (Anne, During-Placement Interview Two)

This direct experience was an interruption for Anne, or an Erfahrung experience. Through the application of a familiar "good" pedagogy in assessment within a student context that was composed of a different set of contextual factors, the direct experience highlighted for Anne that this "good" testing pedagogy was in fact not very good. New meanings emerged, in that multiple-choice tests were now understood as a poor representation of student knowledge. Anne questioned the application of the pedagogy, and further noted a shift in her actions as a teacher in response to the new knowledge gained from her experience. Anne stated:

I'm trying to do a lot more [assessment] with open-ended written questions. So instead of [assessing for] these little snippets of knowledge, those stupid little facts, I ask more broad questions where students can pull in different types of knowledge ... [and connect] with broader concepts. (Anne, During Practicum Interview Two)

In summary, the direct experiences of an international placement situated within Canadian TNE school settings based in Asia provided participants with a comparative experience from which to conceive of different perspectives around understandings and applications of "good" pedagogy that may not have been possible within the context of a home/Canadian based field placement using the same curriculum. As Alexander (2000) states: "Without comparison we simply refashion the world to fit our individual, collective or political interests and remain imprisoned by local or national habits that are too deeply ingrained to allow us to countenance alternatives" (p. 49) thus generating little or no change when experiences "conform to our expectation and confirm it" (Gadamer, 2004, p. 347). Thus, the Erfahrung experiences of the international field placement context provided deeper insights into the participants' own personal values around "good" pedagogy, while also highlighting taken for granted understandings and norms of "good" pedagogy - a finding that is supported by international field placement literature (Driscoll \& Rowe, 2012; Mahan \& Stachowski, 1992; Maynes et al., 2012; Newman, Taylor, Whitehead, \& Planel, 2004). Or as Brindley et al.'s (2009) study noted, perhaps it was the time away from the everyday hectic lives of initial teacher education that allowed the study participants time "to stop and reflect on teaching and learning [while] being out of their comfort zone caused them some dissonance and required [that] they were open-minded in order to make sense of the experience" (p. 531). As Bella noted, "I think I learned that my assumptions were questioned. I was able to see subject matter in a fresh way and then develop new thinking" (PostPlacement Focus Group).

Such a finding is consistent with Santoro and Major's (2012) work that suggests that "dissonance or disequilibrium is an important precursor to learning" (p. 311) and in summarizing Festinger's theory of cognitive dissonance, "when we are presented with information, events and ideas that are in conflict with our existing knowledge and expectations, we are challenged to think differently" (Santoro \& Major, 2012, p. 311). In drawing from outdoor adventure education theory, the experience could be interpreted as a "stretch zone" experience for participants: the middle of three zones, "a place where interest is piqued, our senses are enlivened, and there is some disequilibrium" (Panicucci, 2007, p. 38). That is, the experience is beyond the home-based comfort zone, but not as far as a panic zone 
where "stress is so high that information cannot be integrated" (Panicucci, 2007, p. 39). Interpreted from a Gadamerian perspective, "there is a truth that is revealed in the process of experience (Erfahrung) and that emerges in the dialogical encounter with the tradition" (Bernstein, 1983, p. 152), such as good pedagogy or best practice. Informed by this perspective, we interpreted the experience of teaching in a TNE setting allowed the preservice teachers to reconsider their notions of "good" in pedagogy and best practice. We argue that such experiences can potentially position the pre-service teacher as effective change agents able to reconsider, and be open to, various other notions of "good" in pedagogy and practice as future professionals within their chosen communities.

Some international field placements are more focused on coping with the day-to-day non-schooling experiences of dissonance, such as contending with teaching students living in abject poverty with little access to daily survival needs, leading to dissonance that "may have been too great and too unsettling to promote ... learning" (Santoro \& Major, 2012, p. 319 ) and unlikely to shift, or change teaching practices and understandings of goodness within practices at home. TNE school experiences, on the other hand, may provide enough day-to-day familiarity in relation to techno-rational skills and their previous experiences that participants were able to ponder the embedded understandings of "good" pedagogy within their teaching practice, the curriculum taught, and the resources used to support that teaching both at home and abroad. As Anne stated: "I can say 'I taught' in China, but I really feel as though I was the one being taught and learning more than I could have imagined" (Anne, E-Journal Entry Four).

\section{Discussion}

The results of this study demonstrated that the six participants enlarged and enriched their horizons of understanding good teaching by problematizing the hegemony of Western values embedded within the BC curriculum and schooling, and by expanding and modifying their ideas about good pedagogy. Their intellectual journey, however, was not a simple progression from ignorance to enlightenment, or from question to answer; instead, participants attended to new understandings - and returned to think and reconstruct those understandings again. Generals and particulars informed one another in hermeneutic circles, that is, "structure [s] of understanding within the framework of a formal relation between part and whole ... that [are] constantly augmented by new information" (Kinsella, 2006, "2.1 Seeks understanding", para. 18), a process that can be "both vicious and productive... [and] may spiral outward in breadth" (Higgins, 2010, p. 303). Thus, it is in relating parts (particular experiences) to wholes (general understandings) and vice versa, that the participants constructed their understanding of good teaching. Neither the whole nor the parts existed in isolation: Understanding existed between the interplay of general understanding (what is familiar) and that which interrupts that understanding (what is strange).

Central to this is dialogue, since it is the medium by which understanding is made public. In this study, dialogue was the key resource in expressing understandings of good teaching, allowing for "a coming-into-being of the thing that escapes from the control of the participants” (Grondin, 2003, p. 127). Figure 3 is a representation of how pre-service teachers came to their understandings of good teaching in the direct experience of an international field placement at a transnational school. 


\section{Confirmation of Understandings}

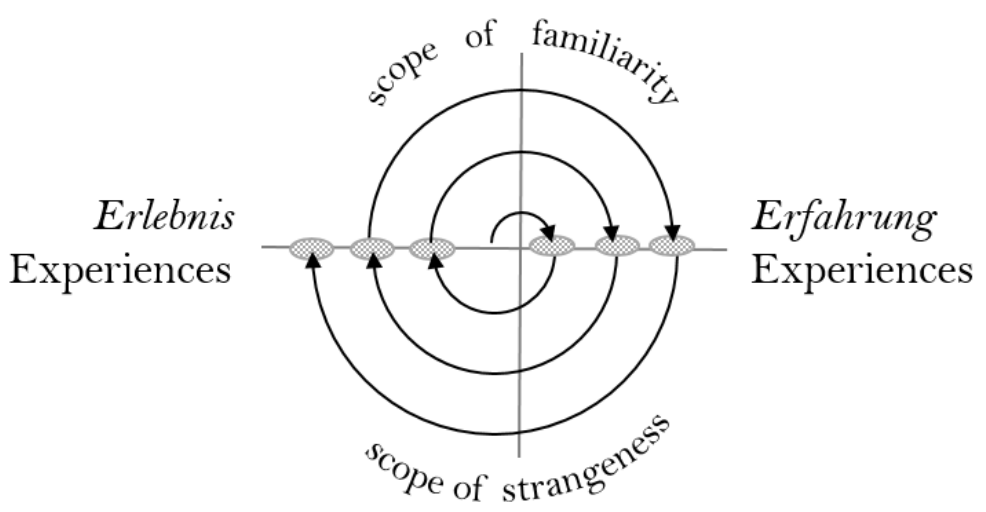

Interruption of Understandings

Figure 3. Processing of understanding good teaching.

Key is the dialogical space between experiences of familiarity (confirmation) and experiences of strangeness (interruptions), or Erlebnis and Erfahrung. The circular process of the conversation moving between familiar and strange is represented by the circular spiral arrows. Study results point to the value of placements in TNE school settings as an opportunity for pre-service teachers to surface the biases and traditions that inform their taken for granted Western conceptions of good teaching, as well as to reflect on and challenge these fundamental understandings. International field placements within a TNE school setting can promote Erfahrung, that is, direct experiences that disturb what has become familiar, a goal that is consistent with a hermeneutic interpretation of understanding which is stimulated by difference and dissonance. "As a consequence of encountering difference, the familiar is transformed; the 'other' also undergoes change in the dialectic of understanding” (Kerdeman, 1998, p. 246).

To foster the genuine conversations; "a conversation [that] has a spirit of its own... bears its own truth within it [to allow] something to "emerge" and henceforth exits" (Gadamer, 2004, p. 385), the dialogical spaces between the familiar and strange is key. In a theory-into-practice, techno-rational paradigm of initial teacher education and the field placement, it is difficult to foster dialogical spaces between the familiar and strange when the focus is on the correct practice versus allowing for a truth to emerge within conversations and dialogue from direct experiences of teaching.

The results of this study have implications for international field placements in initial teacher education programs and highlight TNE school settings as an innovative approach to engendering changes to understandings of good teaching. However, the practice of placing pre-service teachers in international field placements at transnational schools should not aim to create a context that results in "more" internationalized or globalized teachers, but rather be a space for reflective, intimate, and personal thinking around what the possibilities might be for the practice of teaching and understanding the goodness within it. The quasi-familiar context of the transnational school setting provided the participants of this study with a 
"stretch zone" (Panicucci, 2007) - a setting that provided rich potential to surface prejudices informing understandings of good teaching and to interrupt these understandings. Panicucci (2007) explains that "personal growth [does] not occur if there is no disequilibrium in a person's current thinking or feeling [and] learning will shut down if that disequilibrium gets so high that the person enters the panic zone" (p. 39). Indeed, returning to Gadamerian ideas of experience, no event is entirely Erlebnis or Erfahrung; each contains elements of familiarity and incongruity.

\section{Conclusion}

As change agents, teachers, and by extension initial teacher education, must work towards surfacing this perspective on experience if we hope to move beyond and shift the current status quo of replicating a theory-into-practice perspective of initial teacher education. We need to make space for Gadamerian genuine conversations to explore understanding and meanings of good teaching by offering purposely embedded educative experiences (Loughran \& Russell, 2007) in initial teacher education. We argue teaching experiences in TNE schools provide unique opportunities for Erlebnis and Erfahrung and when these are supported with conversation focused on the space between the familiar and strange they can provide the ideal context for exploring understandings of good teaching and to change practices in light of new and shifted understandings. The educational challenge is to find such environments within local contexts that encourage challenging the familiar without being overpowered by what seems incomprehensible. In short, to allow for all preservice teachers to engage in such experiences and conversation within their own domestic borders.

Taking advantage of such opportunities, however, requires substantial support. Simply requiring international field placements of pre-service teachers is unlikely to fuse any educational horizons or initiate change. However, given that hermeneutical understanding requires being open to and engaging with new experiences, much of this study built on scaffolds of dialogic support for participants: each participant was interviewed four times, the researchers talked with them in focus groups pre- and post-international placements and responded to their bi-weekly e-journal reflections - all in an effort to promote genuine conversations around their understandings, interpretations, and actions of good teaching. Partly in response to Britzman's (2003) concern over the lack of theorizing by pre-service teachers about their lived experience, the notion of genuine conversations serves as an important starting point for initial teacher education in general.

Matt explained:

It's messy to think about these things [and] we don't have a lot of these conversations, even in an education program. I don't think I've ever really expressed connections between my classroom set-up, thoughtfulness and good teaching to anyone and I don't think I've heard anyone talk like that . . you don't get [the opportunity] to really kind of go with why you are here [in the program ] and why you want to teach. That's a tough thing and I don't know how you fix that. (Matt, Post-Placement Interview)

In this study, engaging in genuine conversation helped to surface new understandings about good teaching and not simply understandings about the international field placement. This notion and attending to the requirements of Gadamerian dialogue (e.g., focusing on truth between us, being open to the other, believing and doubting) to engage in genuine 
understanding between participants, has important implications for initial teacher education programs. If we hope to change and shift from the epistemological concern, techno-rational approach to understandings of good teaching within initial teacher education, experiences and understandings of good teaching need to be open to a hermeneutic interpretation of understanding. This calls upon initial teacher education to build and foster purposeful dialogical spaces between the familiar and strange. In short, democratic spaces providing "educative experiences purposefully embedded in meaningful pedagogical situations [italics in original]” (Loughran \& Russell, 2007, p. 222).

\section{References}

Alexander, R. (2001). Culture and pedagogy: International comparisons in primary education. Malden, MA: Blackwell Publishers Inc.

Altbach, P. G., \& Knight, J. (2007). The internationalization of higher education: Motivations and realities. Journal of Studies in International Education, 11(3/4), 290305.

Association of Canadian Deans of Education (ACDE). (2005). Accord on initial teacher education. Association of Canadian Deans of Education. Retrieved from http://www.csse-scee.ca/docs/acde/acde_teachereducationaccord_en.pdf

Barthold, L. S. (2012). Hans-Georg Gadamer (1900-2002). Internet Encyclopedia of Philosophy. Retrieved from http://www.iep.utm.edu/gadamer/

Ben-Peretz, M. (2011). Teacher knowledge: What is it? How do we uncover it? What are its implications for schooling? Teaching and Teacher Education, 27(1), 3-9.

Bernstein, R. J. (1983). Beyond objectivism and relativism: Science, hermeneutics, and praxis. Philadelphia: University of Pennsylvania Press.

Biesta, G. (2007). Why "what works" won't work: Evidence-based practice and the democratic deficit in educational research. Educational Theory, 57(1), 1-22.

Brindley, R., Quinn, S., \& Morton, M. L. (2009). Consonance and dissonance in a study abroad program as a catalyst for professional development of pre-service teachers. Teaching and Teacher Education, 25(3), 525-532.

British Columbia Ministry of Education (BCME). (2014). British Columbia Global Education Program: Operating manual for offshore schools. Victoria, BC: BC Ministry of Education. Retrieved from http://www2.gov.bc.ca/assets/gov/education/administration/kindergarten-tograde-12/internationaleducation/is-operatingmanual-2014-15.pdf

Britzman, D. P. (2003). Practice makes practice: A critical study of learning to teach. Albany, NY: State University of New York Press.

Brumberger, E. R. (2007). Making the strange familiar: A pedagogical exploration of visual thinking. Journal of Business and Technical Communication, 21(4), 376-401.

Buczynski, S., Lattimer, H., Inoue, N., \& Alexandrowicz, V. (2010). Developing a policy for an international experience requirement in a graduate teacher education program: A cautionary tale. Teaching Education, 21(1), 33-46.

Bullock, S. M. (2011). Inside teacher education: Challenging prior views of teaching and learning. Rotterdam, Netherlands: Sense Publishers.

Byram, M. (2008). From foreign language education to education for intercultural citizenship: Essays and reflections. Clevedon, England: Multilingual Matters.

Canadian Information Centre for International Credentials (CICIC). (2019). Directory of offshore schools and international education resources. Retrieved from 
https://www.cicic.ca/982/perform_an_advanced_search_in_the_directory_of_offsh ore_schools_and_international_education_resources.canada

Christou, T. M., \& Bullock, S. M. (2013). The history of education as a frame for teacher education. In T. M. Christou, \& S. M. Bullock (Eds.), Foundations in teacher education: A Canadian perspective (Vol. 1, pp. 19-29). Canadian Association of Teacher Education. Retrieved from https://docs.google.com/file/d/oB2i27L6z 1 IlUTH15OTFZN2lFdkU/edit

Cochran-Smith, M. (2004). The problem of teacher education. Journal of Teacher Education, 55(4), 295-299.

Crocker, R. K., \& Dibbon, D. C. (2008). Teacher education in Canada: A baseline study. Kelowna, BC: Society for the Advancement of Excellence in Education.

Culligan, K., \& Kristmanson, P. (2014). Becoming teacher: Influences of a practicum in China. In L. Thomas (Ed.), Becoming teacher: Sites for teacher development in Canadian teacher education (pp. 62-93). Canadian Association for Teacher Education. Retrieved from https://docs.google.com/file/d/oBwVGDOGBDzJdR1R2VGZvakZjUDQ/edit

Cushner, K., \& Mahon, J. (2002). Overseas student teaching: Affecting personal, professional, and global competencies in an age of globalization. Journal of Studies in International Education, 6(1), 44-58. doi:10.1177/1028315302006001004

Driscoll, P., \& Rowe, J. (2012). Broadening the lens: an investigation of student teachers' changing perceptions of pedagogy following a teaching placement in a primary school in mainland Europe. Education 3-13, 40(4), 417-431. doi: 10.1080/03004279.2012.691375

Eisner, E. W. (2002). From episteme to phronesis to artistry in the study and improvement of teaching. Teaching and Teacher Education, 18(4), 375-385. doi:0.1016/So742$051 \mathrm{X}(02) 00004-5$

Freeman, M. (2011). Validity in dialogic encounters with hermeneutic truths. Qualitative Inquiry, 17(6), 543-551. doi:10.1177/1077800411409887

Gadamer, H. G. (2004). Truth and method (2nd ed.). London, UK: Continuum International Publishing Group.

Gambhir, M., Broad, K., Evans, M., \& Gaskell, J. (2008). Characterizing initial teacher education in Canada: Themes and issues. Prepared for the International Alliance of Leading Education Institutes. Toronto: Ontario Institute in the Study of Education, University of Toronto.

Grondin, J. (2003). The philosophy of Gadamer. (K. Plant, Trans.) Montreal, QC: McGillQueen's University Press

Higgins, C. (2010). A question of experience: Dewy and Gadamer on practical wisdom. Journal of Philosophy of Education, 44(2-3), 301-333. doi:10.1111/j.14679752.2010.00757.x

Kabilan, M. K. (2013). A phenomenological study of an international teaching practicum: Pre-service teachers' experiences of professional development. Teaching and Teacher Education, 36, 198-209. doi:10.1016/j.tate.2013.07.013

Kerdeman, D. (1998). Hermeneutics and education: Understanding, control, and agency. Educational Theory, 48(2), 241-266. doi:10.1111/j.1741-5446.1998.00241.x

Kinsella, E. (2006). Hermeneutics and critical hermeneutics: Exploring possibilities within the art of interpretation. Forum Qualitative Sozialforschung/Forum: Qualitative Social Research, 7(3). doi:10.17169/fqs-7.3.145 
Knight, J. (2016). Transnational education remodeled: Toward a common TNE framework and definitions. Journal of Studies in International Education, 20(1), 34-47. doi: $10.1177 / 1028315315602927$

Knight, J., \& McNamara, J. (2015). The impact of transnational education in receiving countries. International Higher Education, 82, 3-5. doi: 10.6017/ihe.2015.82.8862

Lee, J. (2011). International field experience - What do student teachers learn? Australian Journal of Teacher Education, 36(10), 1-22. doi:10.14221/ajte.2011v36n10.4

Lim, F. C. B. (2016). Transnational education in Chinese secondary education. International Higher Education, 87, 12-13. doi:10.6017/ihe.2016.87.9503

Lincoln, Y. S., \& Guba, E. G. (1985). Naturalistic inquiry. Beverly Hills, CA: Sage Publications.

Liu, C., \& Sui, X. (2014). Understanding the Platonic dialogue from the perspective of Gadamer's hermeneutics. Theory and Practice in Language Studies, 4(4), 758-765. doi:10.4304/tpls.4.4.758-765

Loughran, J., \& Russell, T. (2007). Beginning to understand teaching as a discipline. Studying Teacher Education, 3(2), 217-227. doi:10.1080/17425960701656619

Mahan, J., \& Stachowski, L. (1992). Self-reported reshaping effects of foreign student teaching upon young teachers. Education, $112(3)$, 329-351.

Malewski, E., Sharma, S., \& Phillion, J. (2012). How international field experiences promote cross-cultural awareness in preservice teachers through experiential learning: Findings from a six-year collective case study. Teachers College Record (1970), 114, 144.

Martin, A. K., \& Russell, T. (2005). Listening to preservice teachers' perceptions and representations of teacher education programs. In J. E. Brophy \& S. E. Pinnegar (Eds.), Learning from Research on Teaching: Perspective, Methodology, and Representation Advances in Research on Teaching (pp. 3-39). doi:10.1016/S1479-3687(05)11001-3

Maynes, N., Allison, J., \& Julien-Schultz, L. (2012). International practica experiences as events of influence in a teacher candidates' development. McGill Journal of Education, 47(1), 69-91.

McGregor, C., Sanford, K., \& Hopper, T. (2010). <Alter >ing experiences in the field: Next practices. In T. Falkenberg, \& H. Smits (Eds.), Field experiences in the context of reform of Canadian teacher education programs (pp. 297-315). Winnipeg, MN: University of Manitoba. Retrieved from http://umanitoba.ca/education/TEResearch/Book\%202009\%20(Volume\%202).pdf

Moules, N. J., McCaffrey, G., Field, J. C., \& Laing, C. M. (2015). Conducting hermeneutic research: From philosophy to practice. New York, NY: Peter Lang Publishing.

Moules, N. J., McCaffrey, G., Morck, A. C., \& Jardine, D. W. (2011). On applied hermeneutics and the work of the world. Journal of Applied Hermeneutics, 1, 1-5. doi:10.11575/jah.voio.53186.

Myers, E. (1997). Some benefits of an education abroad programme for elementary preservice teachers. Education, 117(4), 579-583.

Newman, E., Taylor, A., Whitehead, J., \& Planel, C. (2004). 'You just can't do it like thatit's just wrong!' impressions of French and English trainee primary teachers on exchange placement in primary schools abroad: The value of experiencing the difference. European Journal of Teacher Education, 27(3), 285-298. doi:10.1080/0261976042000290804 
Panicucci, J. (2007). Cornerstones of adventure education. In D. Prouty, J. Panicucci, \& R. Collinson (Eds.), Adventure education, theory and applications (pp. 33-48). Windsor, ON: Human Kinetics.

Roberts, J. W. (2005). Disney, Dewey, and the death of experience in education. Education and Culture, 21(2), 12-30.

Russell, T., Martin, A., O'Connor, K., Bullock, S., \& Dillon, D. (2013). Comparing fundamental conceptual frameworks of teacher education in Canada. In L. Thomas (Ed.), What is Canadian about teacher education in Canada? Multiple perspectives on Canadian teacher education in the twenty-first century (pp. 10-35). Canadian Association of Teacher Education.

Santoro, N. (2009). Teaching in culturally diverse contexts: what knowledge about 'self' and 'others' do teachers need? Journal of Education for Teaching, 35, 33-45. doi: 10.1080/02607470802587111

Santoro, N., \& Major, J. (2012). Learning to be a culturally responsive teacher through international study trips: transformation or tourism? Teaching Education, 23(3), 309322. doi:10.1080/104762 10.2012.685068

Stachowski, L. L., \& Sparks, T. (2007). Thirty years and 2,000 student teachers later: An overseas student teaching project that is popular, successful, and replicable. Teacher Education Quarterly, 34(1), 115-132.

Trilokekar, R. D., \& Kukar, P. (2011). Disorientating experiences during study abroad: Reflections of pre-service teacher candidates. Teaching and Teacher Education, 27(7), 1141-1150. doi:10.1016/j.tate.2011.06.002

van Manen, M. (1990). Researching lived experience: Human science for an action sensitive pedagogy. Albany, NY: State University of New York Press.

Wang, F., \& Clarke, A. (2014). The practicum experiences of English language major student teachers during a period of profound curriculum reform in China.

International Journal of Educational Development, 36,108-1 16.

Warnke, G. (1987). Gadamer: Hermeneutics, tradition and reason. Oxford, UK: Polity Press.

Warnke, G. (2002). Social identity as interpretation. In J. Malpas, U. Arnswald, \& J. Kertscher (Eds.), Gadamer's century: Essays in honor of Hans-Georg Gadamer (pp. 307329). Cambridge, MA: The MIT Press.

\section{About the Authors}

Marian Riedel is Chair of Graduate Programs in the Faculty of Education at Vancouver Island University. She holds an EdD in Educational Leadership and Policy from the University of British Columbia and teaches at both the undergraduate and graduate levels. Serving as the principal investigator in this study, Marian Riedel's research interests include hermeneutics as a philosophy of interpretation to explore understandings in teacher education, specifically how this relates to direct experiences of teaching, international education, Indigenous understandings and alternative curriculum. She also supervises graduate students in VIU's Master's of Educational Leadership program, continues to support international field placements for pre-service teachers, and is passionate about challenging all her students to explore how it is that they know what they know.

Rachel Moll is Associate Dean in the Faculty of Education at Vancouver Island University. She holds a PhD in Curriculum and Instruction from the University of British Columbia and teaches at both the undergraduate and graduate levels. Rachel Moll's research interests include science education, teacher education, and complexity thinking. She is cochair of Vancouver Island University's participation in an international network of 
researchers examining education for sustainable development and Indigenous education. She regularly supervises graduate students in VIU's Master's of Educational Leadership program. 